\title{
Aprendendo com o Axé: processos educativos no terreiro e o que as crianças pensam sobre ele e a escola
}

\author{
Amurabi Oliveira $^{1}$ \\ Universidade Federal de Santa Catarina, SC, Brasil \\ E-mail:amurabi_cs@hotmail.com \\ Kleverton Arthur de Almirante ${ }^{2}$ \\ Universidade Federal de Alagoas, AL, Brasil \\ E-mail:klevertonjornalista@gmail.com
}




\section{Resumo}

O presente trabalho visa discutir os processos de aprendizagem vivenciados por crianças no Candomblé, utilizou-se, para tanto, da pesquisa etnográfica que vem sendo realizada no terreiro Axé Vodun Tó Yeyê Apará, na cidade de Maceió, capital de Alagoas. Partindo de uma das principais contribuições da Antropologia para o campo da Educação, que é justamente o alargamento desse conceito para além de sua concepção escolar, e da Antropologia da Criança, que nos faz reconhecer a especificidade da produção cultural das crianças, compreende-se que dentro do terreiro são produzidos saberes diversos aprendidos de várias formas por esses agentes. No caso específico das crianças, há uma questão singular, pois, concomitante aos processos de aprendizagem vivenciados no terreiro, pode-se perceber que elas estão submetidas a uma educação formal, escolarizada, que tendenciosamente não produz diálogos com o que é aprendido em outros espaços. Contudo, o que interessa aqui é compreender como esses sujeitos articulam o que é vivenciado nestes dois espaços de aprendizagem, tanto a escola como o terreiro. Neste trabalho, almeja-se aprofundar as discussões sobre: a) os processos de aprendizagem no terreiro; e b) como as crianças percebem a ligação entre o que é aprendido no terreiro e o que é aprendido na escola.

Palavras-chave: Candomblé. Antropologia da Educação. Antropologia da Criança.

\section{Abstract}

This paper aims to discuss the learning processes experienced by children in Candomble, using for both the ethnographic research that has been done in the terreiro Axé Vodun Tó Yeyê Apará, in Maceió, capital of Alagoas. Starting from one of the main contributions to the field of Anthropology of Education, which is precisely the extension of this concept beyond its design school, and Anthropology of the Child, which makes us recognize the specificity of production cultural children, understand that within the yard are produced various knowledge learned in various ways by these agents. In the specific case of children, we have a singular issue, therefore, concurrent learning processes experienced in the terreiro, they are subjected to a formal education, schooling, which does not produce so biased dialogues with what is learned in other spaces. However, we are interested in understanding how these subjects articulate what is experienced in these two learning spaces, both the school and the yard. In this work, we aim to deepen the discussions about: a) the learning processes in the terreiro b) how children perceive the connection between what is learned in the terreiro and what is learned in school.

Keywords: Candomblé. Anthropology of Education. Anthropology of the Child. 


\section{Introdução}

Tistoricamente, a escola tem se constituído como um espaço de 1 socialização próprio das crianças (Ariés, 1981), compreendida por alguns autores como um lócus por excelência de socialização (Durkheim, 2011). Contudo, devemos reconhecer que a escola é também um espaço de sociabilidades (Gusmão, 2003), no qual os diversos sujeitos envolvidos trocam experiências e vivenciam a dimensão da alteridade de uma forma que não podem realizar no seio familiar.

Todavia, é preciso reconhecer também que a escola não é um espaço culturalmente neutro (Macedo, 2010), e que algumas identidades serão reconhecidas e reforçadas no espaço escolar, enquanto outras serão negadas e refutadas - o que só poderá ser compreendido ante uma leitura cuidadosa das contradições culturais existentes na sociedade mais ampla.

Nesse sentido, cabe destacar, por um lado, as identidades que historicamente são negadas no espaço público, que tangenciam as dimensões de gênero, étnica, religiosa, dentre outras - dimensões estas que são separáveis analiticamente, porém interligadas em termos de realidade empírica. Mesmo diante das transformações ocorridas no último século, e de forma mais intensa nas últimas décadas, quando se tem, por exemplo, a passagem das religiões afro-brasileiras de étnicas para universais (Prandi, 2001), mediante um intenso processo de embranquecimento delas (Ortiz, 1999), ainda se verifica no país um intenso preconceito religioso atrelado à questão étnica que se reverbera no espaço escolar. (Caputo, 2012)

Considerando tais apontamentos, propõe-se aqui investigar a realidade das crianças de Candomblé3 a partir da etnografia desenvolvida 
no terreiro Axé Vodun Tó Yeyê Apará, na cidade de Maceió. O objetivo é investigar os saberes produzidos neste terreiro, ensinados às crianças em situação escolar regularizada, para então analisar sua relação com a educação escolar; ainda que se deva reconhecer aqui os limites dessa distinção, uma vez que ela nos é bastante útil em termos analíticos, porém na realidade dos sujeitos pesquisados os limites entre essas duas realidades são bem tênues.

Cabe pontuar que a produção acadêmica acerca da relação entre o Candomblé e a educação é recente e tem partido em sua maioria das perspectivas multiculturais e interculturais do ensino (Candau; Leite, 2012), muitas vezes lançando mão de conceitos teóricos e propostas metodológicas da Antropologia. Nos registros feitos no banco de teses da Coordenação de Aperfeiçoamento de Pessoal de Nível Superior (CAPES), o número de pesquisas realizadas em todo o Brasil que relacionaram precisamente as temáticas de "Candomblé, educação e escola" foi 15 em nível de Mestrado e 4 em nível de Doutorado. Voltando-se para a realidade alagoana, há um único trabalho desenvolvido em nível de pós-graduação (Belo, 2012), pesquisa realizada a partir de uma perspectiva historiográfica que, como algumas outras, figura fora desses registros.

Neste caso, trata-se aqui de uma pesquisa etnográfica cujo foco neste artigo remete às observações realizadas no espaço do terreiro e em algumas entrevistas, que, pela peculiaridade de envolver pesquisas com crianças, mostra-se como um grande desafio para a pesquisa (Pires, 2007). A etnografia foi pensada como metodologia para entender as experiências de aprendizagem das crianças, buscando romper com o "abstracionismo pedagógico" (Azanha, 1992) presente em muitas investigações que se voltam para a realidade educativa. Desse modo, posiciona-se aqui, em termos metodológicos, de forma afirmativa com relação à utilização da etnografia na pesquisa educacional, reconhecendo a indissociabilidade entre teoria e método nesta incursão. (Oliveira, 2013a, 2003c)

Vale dizer que um dos autores deste artigo faz parte do universo religioso do terreiro no qual essas crianças são pesquisadas, o que traz um desafio ainda maior, ao pensar o processo de estranhamento da realidade que nos é familiar, o que é um pressuposto básico da 
antropologia como coloca Damatta (1978). A antropologia mostra-se complexa, portanto, a busca por

[...] tirar a capa de membro de uma classe e de um grupo social específico para poder - como etnólogo - estranhar alguma regra social familiar e assim descobrir (ou recolocar, como fazem as crianças quando perguntam os "porquês") o exótico no que está petrificado dentro de nós pela reificação e pelos mecanismos de legitimação. (Damatta, 1978, p. 28-29)

O processo de imersão como pesquisador em um universo já conhecido, do qual se faz parte, apresenta-se como uma atividade árdua, pois um empirismo ingênuo poderia apontar para um processo simples, sem grandes entraves para o desenvolvimento da pesquisa. Há de se reconhecer aqui que, no momento da iniciação como pesquisador, se está passível de encontrar entraves, como estes: entrada, constrangimento, estranhamento, identificação, aceitação, reconhecimento e alguns sentimentos que permeiam o caminho envolvente, cheio de riscos e de aventureira com relação à pesquisa. A sensação registrada foi de abalo e fragilidade, ainda que as crianças e os seus adultos tivessem confiança em quem as entrevistava.

Mesmo diante de uma realidade conhecida, tratou-se aqui de imergir em outro sistema simbólico, tendo em vista que se buscava investigar a cultura própria do universo infantil, algo que se torna objeto de reflexão recente na antropologia e que precisa ser desbravada pelos antropólogos (Cohn, 2005; Corsaro, 2005; Pires, 2007; 2009, 2010; Tassinari, 2011), ainda que não se neguem aqui as contribuições fundamentais de alguns estudos pioneiros, em especial de Margaret Mead. No caso específico de nossa pesquisa é possível perceber um processo de elaboração de uma interpretação particular sobre o que é aprendido no espaço do terreiro e na escola, e da relação que seus saberes estabelecem.

As crianças entrevistadas foram W e Y, de 9 e 12 anos, respectivamente. Optou-se por não dar a elas um codinome, para que não fosse alterado o reconhecimento da identidade que elas carregam, tampouco preferiu-se que elas escolhessem outros nomes pela mesma 
razão. Essas são as iniciais de seus nomes na tentativa de preservar a identidade individual de cada uma na pesquisa.

W estuda a $2^{a}$ série ( $3^{\circ}$ ano) do Ensino Fundamental I em uma escola privada distante seu de bairro. Y estuda a $5^{\mathrm{a}}$ série $\left(6^{\circ}\right.$ ano $)$ do Ensino Fundamental II em uma escola pública do entorno do terreiro. W tem a pele negra, como seus pais, que também são membros do terreiro, os cabelos volumosos e cacheados, brinca como todas as crianças e ainda não é filha de santo ${ }^{4}$ raspada ${ }^{5}$ na casa. Y é uma garota de pele branca, sua mãe também é membro do terreiro. Y está com os cabelos curtinhos devido à sua recente iniciação com raspagem e dialoga muito bem sobre diferentes assuntos.

Foram escolhidass essas duas entrevistadas por compreender que as elas representam casos emblemáticos para nossa compreensão em torno da aprendizagem vivenciada no terreiro, pois são as duas crianças mais participativas, tanto nas atividades rituais do terreiro, quanto nas brincadeiras e na participação da pesquisa - representando também dois extremos de nossas crianças de terreiro: as raspadas e as que ainda não são raspadas. Sendo assim, deve-se ter em mente que o estudo de casos particulares pode nos levar a questões mais amplas (Geertz, 1989), em especial considerando que é preciso relacionar o descoberto em tais casos com a dimensão da totalidade. (Magnani, 2009; Laplantine, 2011)

\section{O Tempo-Espaço de Aprendizado}

Para a melhor compreensão do que será explorado neste artigo, será realizada aqui uma breve contextualização acerca do nosso lócus de pesquisa ${ }^{6}$, afinal, realizando uma paráfrase do que Geertz (1989) afirma, será estudado não o terreiro, mas no terreiro. É nesse espaço que se desenvolvem relações interacionais de ensino-aprendizagem ${ }^{7}$ das visões/leituras de mundo, da ritualística e as múltiplas sociabilidades entre os agentes pesquisados. Os laços interacionais de uma comunidade-terreiro são mantidos no tempo sob a forma de famíliasde-santo (Verger, 2007), que constituem tradicionalmente a unidade social da cultura de um terreiro. Atrelado a esse elemento pode-se dizer que o tempo é elemento primordial no Candomblé. O próprio 
Candomblé - uma reformulação do modus vivendi africano no Novo Mundo - tem se adaptado aos novos modos de vivência da sociedade com o passar dos tempos. (Ortiz, 1999; Prandi, 2004)

O terreiro pesquisado chama-se Axé Vodun Tó Yeyê Apará. É uma casa regida pela divindade aquática de origem nagô-iorubá $O$ xum $^{8}$. Esse terreiro está localizado numa região periférica de um dos bairros da parte alta da cidade de Maceió - o bairro do Tabuleiro do Martins. O acesso a ele é dificultado pelas várias estradas de barro e ruas não calçadas da região.

A casa de axé é dirigida pelo zelador de culto Marcos de Apará, conhecido pelo hierônimo de Aparálòmí - que significa que Oxum recebe o raio nas águas - e pela mãe- pequena Sandra de Aganjú, conhecida como Obágànjèwí - que significa que Aganjú é o rei das lavas vulcânicas [correntes defogo]. É um terreiro que, na forma espacial onde está localizado atualmente, data do ano de 2007. Porém seu axé9 data do ano de $1979^{10}$, tendo a partir desse período duas localizações (reinaugurações de axé), sendo a segunda em 1999.

O calendário de festas dessa casa baseia-se no modelo jeje-nagô, ou nagô-vodun - próprio do Bravun - de culto aos ancestrais:

a) No mês de janeiro há a festa de abertura do ano da casa.

b) Abril é festivo para as divindades da caça, da provisão, do sustento, da fartura, da proteção, da colheita, da agricultura e do plantio do milho, encabeçada pelos irmãos Ogum e Odé.

c) Maio é devotado à festa para a divindade aquática feminina que rege a maternidade e o próprio terreiro pesquisado, Oxum, junto a seu filho Logum.

d) O mês de junho é de festa para Xangô (Badé), celebrando a colheita do milho plantado no mês de abril e regado pelas águas das chuvas de maio. Duas das esposas dele, Obá e Oyá (o mesmo que orixá Yansã), também são convidadas a participar da festa ao trovão que anunciou a boa colheita e ao fogo que cozinha o alimento colhido.

e) Agosto é o mês de festa para o rei Bessén (adotado no Ketu como orixá Oxumarê), sua mãe Nanã e seus irmãos Agué (divindade próxima ao orixá Ossãe/Ossaim/Ossayin) e Sakpatá. 
f) Outubro é mês de festejar as divindades infantis e os gêmeos Ibejí, que são relacionados ao nascimento de novas crianças, dando espaço para os erês ${ }^{11}$ brincarem.

g) No mês de novembro, as entidades das ruas, encruzilhadas e passagens, e os ancestrais ligados à territorialidade brasileira, os caboclos e mestres de Jurema, são homenageados.

h) Quem fecha esse ciclo com a festa de encerramento do ano da casa é Oxalá com sua esposa Yemonjá, que é responsável pelas cabeças, inclusive a do novo ano.

Os meses de fevereiro, março, julho e setembro ficam resignados às obrigações de iniciação, confirmação de tempo e demais devoções individuais/coletivas ${ }^{12}$ da comunidade-terreiro. Essas obrigações, como são chamadas, são as ações de devoção que confirmam os laços de parentesco com a família-de-santo daquela casa. Por meio das obrigações é que se pratica a participação dos membros do terreiro na casa de axé.

Observa-se que, nesta casa, a realização das obrigações acontece mediante uma agenda ritual. A agenda ritual organiza as atividades necessárias a esta ou àquela obrigação. Por exemplo, quando a obrigação de integrar o corpo iniciático da casa é a raspagem da cabeça com reclusão mínima de 21 dias de aprendizado intenso, a agenda ritual engloba atividades como os ebós ${ }^{13}$ de limpeza, o apanhado das folhas usadas para a produção dos banhos e chás, o culto à cabeça do iniciando, o sacrifício de animais, o ensino da linguagem comunicativa e da expressão dançante, os preparativos para a festa de saída da reclusão e afazeres diários domésticos como cozinhar, lavar roupas, varrer etc. Tanto nas atividades rituais, quanto nos afazeres domésticos, às crianças é confiada a capacidade de execução. São ensinadas a desempenhar funções ritualísticas por, justamente, serem consideradas preparadas para tal.

\section{Que Aprendem}

Buscou-se investigar os processos de aprendizagem vivenciados pelos membros do terreiro, entre esses membros, as crianças, que, como já foi pontuado, possuem uma cultura própria e uma visão sui 
generis sobre o que ocorre nesse espaço. Esses aspectos implicaram que, mesmo ante uma realidade já conhecida, foi necessário realizar um movimento de reconhecimento desse universo, encarando o fato de que a cultura é sempre distributiva (Barth, 2001), ou seja, mesmo quando participa-se do mesmo grupo social, vive-se experiências diversas, acessíveis a nós apenas por meio da interpretação.

Não nos limitamos às crianças que já eram raspadas na casa (iyawôs) - nosso olhar se voltou para todas as outras crianças que se identificavam com aquele universo cultural e religioso e vivenciavam o Candomblé como sua religião (abiyãs).

Essas crianças sabem palavras, frases, cânticos e rezas em idiomas como o iorubá, o fongbé, o quimbundo, etc., demonstrando destreza em sua utilização, e apontando para um processo de incorporação delas em seu universo simbólico. Pode-se interpretar esse fenômeno como parte de uma resistência cultural tão forte que permanece e se expande na atualidade, verificando mesmo o que alguns pesquisadores apontam como um processo de reafricanização dos cultos afro-brasileiros, que ocorre ao mesmo tempo em que as religiões de matrizes africanas deixam de ser religiões étnicas no sentido mais estrito do termo. (Prandi, 2004)

Além de apresentarem conhecimentos referentes a línguas africanas ${ }^{14}$, nessas crianças são desenvolvidas outras leituras de mundo $^{15}$ particulares, sensivelmente distintas daquelas encontradas na dinâmica religiosa hegemônica no nosso país e em grande parte do Ocidente. Por meio dessa cultura é que as crianças constroem as suas próprias cosmovisão e identidade, uma vez que estas são construções socioculturais que se relacionam diretamente com a experiência não só individual como também coletiva.

As crianças passam a conhecer o uso medicinal de certas plantas e a mágica substancial química contida em tudo isto: chás, banhos, decocções, emplastos, etc. A usabilidade ritual de alguns elementos naturais - vegetais como ervas, grãos e raízes; minerais como o sal, o carvão, as pedras e as águas de mares, rios e fontes; animais como integrantes da base alimentar onívora e a importância da vida e do sangue animal - notórios no Candomblé, o que é algo bastante interes- 
sante, uma vez que tais conhecimentos aprendidos neste espaço não são valorizados no espaço escolar, sendo mesmo negados muitas vezes.

Na ritualística sacrificial que essas crianças participam, isto é, nos rituais de corte de animais oferecidos à alimentação das divindades em conjunto com a comunidade participante dos ritos internos e públicos (as festas), observa-se que elas aprendem atividades de cozimento das comidas animais e de origem vegetal, o que se apresenta como uma atividade que se liga ao mesmo tempo ao mundo sagrado e ao profano, pois trata-se de uma aprendizagem que passa a ser utilizada no templo e fora dele. Esse processo obviamente transparece as relações de dominação e tensões postas na relação entre o mundo adulto e o das crianças, tendo em vista que:

Os adultos assumem o papel decisivo na determinação das condições de vida das crianças, não apenas por ser nesta geração que se encontram os detentores do poder político e social, mas também porque eles marcam a infância pela adopção de processos de administração simbólica das crianças (Sarmento, 2004), através do exercício contínuo de um poder normativo, que se realiza tanto ao nível da produção de conteúdos significativos sobre o que é apropriado ou não para as crianças (por exemplo, a propósito das práticas de consumo, das horas de sair, das formas de saudação aos mais velhos, de hábitos legitimados ou proibidos), quanto na interacção face a face e no desempenho dos seus papeis de pais, professores, formadores, funcionários das instituições que lidam com crianças, etc. (Sarmento, 2011, p. 584)

Outro momento em que tais questões aparecerem é durante as festas em que toda a comunidade executa os passos das danças que aprendeu. A dança ${ }^{16}$ é uma forma de comunicação pela expressão do corpo nas festas, sendo esses eventos que reúnem pessoas de diversas origens e diferentes estratos sociais, mas que mantêm em comum a crença nas divindades de origem africana e afro-brasileiras. Inúmeros pratos de comida são oferecidos durante as festas numa forma de comunhão, devemos reconhecer, portanto, que a dança, a festa e a comida são elementos centrais para se compreender a lógica das religiões afro-brasileiras (Motta, 1982, 1995). Segundo Fonseca (1997, p. 271): 
Na verdade, as músicas e as danças ocupam uma posição central nas festas realizadas nos terreiros. Conforme vimos, é através dos pontos cantados, isto é, cantos sagrados, para saudar e evocar os deuses, e dos seus ritmos, tocados pelos Ogâs, que as entidades "descem" à terra. Se, por um lado, é necessário cantar com todo o entusiasmo e vigor para agradar às divindades, por outro, é importante também acompanhar os cantos com as respectivas danças, onde as coreografias estão relacionadas com as histórias míticas desses deuses. Deste modo, as músicas ouvidas e cantadas são transformadas em movimentos sagrados, movimentos que remontam às origens, tempo mítico dos deuses.

Desse modo, os laços estabelecidos dentro dos terreiros de Candomblé são modos legítimos de socialização com a cultura e a religiosidade com a qual essas crianças se identificam. Em todo o caso, é importante destacar que muitos desses elementos são retraduzidos na cultura das crianças, em especial por meio da ludicidade, tendo em vista que diferentemente dos adultos as crianças brincam continua e abnegadamente, não havendo uma distinção clara entre o brincar e as "coisas sérias" (Sarmento, 2004). Observa-se que, corriqueiramente, as crianças faziam brincadeiras que imitam a ritualística e o transe nos momentos em que as atividades rituais acabavam de ser executadas e partia-se para o descanso. Um grupo com cerca de cinco crianças de 4 a 12 anos brincava de dançar os passos executados pelas divindades em transe, imitando as funções dos iyawôs, egbômis e cargos de ogãs e ekédjis até que fossem chamados para uma nova atividade ritual.

Interessante destacar um elemento trazido pela pesquisa de Falcão (2010), em que a autora aponta para as diversas perspectivas sobre as brincadeiras infantis presentes no ponto de vista dos adultos e das próprias crianças:

Em entrevista, Regiane afirma que vê com bons olhos essa inserção das crianças desde cedo na religião, pois que compara essa inserção com o catecismo católico. O problema, para ela, é que as crianças passam a saber demais, e sabem até mais que alguns filhos-de-santo mais velhos, o que para Regiane é quase uma vergonha, além de que as crianças tornariam públicos alguns 
segredos quando de suas brincadeiras. Regiane conta que é comum os sobrinhos e sua filha brincarem de Candomblé na escola, e que às vezes eles banalizam procedimentos muito caros à religião. Para Camilo, as brincadeiras de Candomblé são uma forma de assumir a religião de sua família, a qual nem ele nem seus primos parecem ter vergonha. Carol chama de - burros os colegas que falam mal do Candomblé. Regiane fala de filhos de santo com mais de sete anos de santo que não sabem certos procedimentos que sua filha Carol de 10 anos sabe. Cristina já olha isso com mais orgulho em dizer que seus filhos e sobrinhos sabem muito mais de religião do que os filhos de santo de sua mãe, porque as crianças, nas palavras de Cristina, - vivem o Candomblé. (Falcão, 2010, p. 64-65)

O que parece interessante destacar é que a lógica da distinção entre o que é sério e o que é brincadeira é muito própria do mundo adulto, o que não necessariamente faz sentido para o universo da criança, sendo esse um dos principais instrumentos de aprendizagem deles. Esse é um dado importante tendo em vista que devemos reconhecer que há "[...] uma diversidade de experiências culturais de ensino e aprendizagem" (Cohn, 2005, p. 37). As crianças aprendem comportamentos básicos de obediências familiar, religiosa e social no terreiro. São instruídas a como se portar diante de diversas situações e a como agir em diferentes $\operatorname{casos}^{17}$. Também na pesquisa de Caputo (2012), a questão do brincar mostrou-se como algo relevante para compreender a aprendizagem vivenciada pelas crianças no terreiro.

Para além das questões explicitamente postas Rabelo e Santos (2011) chamam a atenção para o fato de que no candomblé há também uma aprendizagem essencialmente corporal. Segundo as autoras:

Aprender nestes contextos não é primeiramente adquirir um domínio intelectual do que se passa, é ajustar-se à cena, ser capaz de responder corporalmente a seu apelo e, desta forma, tornar-se parte dela. É um processo em que sensibilidades são despertadas, desenvolvidas e canalizadas rumo à formação de hábitos e disposições mais duradouras para agir. (Rabelo; Santos, 2011, p. 190) 
Percebe-se desse modo que pensar os processos de aprendizagem vai para além dos conhecimentos adquiridos, perpassando a construção de um estar no mundo, é possível afirmar, portanto, que a imersão no Candomblé implica a construção de um dado habitus, mais especificamente de uma determinada héxis corporal, para se utilizar das categorias de Bourdieu (1983). Tal questão mostra-se de suma importância para nossa problemática, tendo em vista que o corpo é um importante elemento na construção das carreiras escolares, havendo um verdadeiro julgamento corporal, utilizado como elemento de exclusão no universo da escola. (Oliveira, 2013b)

\section{Como Aprendem}

As crianças são ensinadas no Candomblé mediante a observação, ainda que a aprendizagem não se dê apenas a partir disso, uma vez que, como já se mencionou, a brincadeira possui uma centralidade no processo de aprendizagem das crianças no terreiro. Ainda que não seja ensinado "como brincar", portanto, a aprendizagem é, por excelência, um processo criativo. Tais questões nos levam a problematizar o próprio processo educativo, em especial quando o relacionamos com o conceito-chave de socialização, compreendido, por vezes, como um processo por meio do qual os adultos, portadores da cultura, "transmitem-na" para as crianças.

Contudo, é preciso considerar algumas questões postas pela Antropologia da Criança mais recentemente, como anuncia Pires (2010, p. 148):

O que quero propor é que esses conceitos de cultura e sociedade, implicados na noção de socialização, tal como descrita previamente, não parecem dar conta de compreender o que se passa no mundo adulto nem, muito menos, no mundo infantil. A cultura não reside estática na cabeça dos adultos, esperando ser enviada passivamente para as cabeças infantis. Abordagens sobre a infância que tratam as crianças como agentes sociais, produtores de cultura e personagens históricos (só para citar alguns exemplos: Bluebond-Langner, 1978; Briggs, 1992; Cohn, 2002; Corsaro, 2003, 2005; Nascimento, 2007; 
Nunes, 1999; Pires, 2009; Tassinari, 2001; Toren, 1990, 1999), levam em consideração que: 1) não há uma idade única para o aprendizado cultural: não apenas as crianças aprendem, mas os adultos não cessam de aprender; 2) as crianças aprendem tanto quanto ensinam, dos/aos seus pares e dos/aos adultos; 3 ) aprendizagem não se faz apenas por via consciente e racional, mas também através de outras maneiras de conhecer e aprender.

No caso do Candomblé, isso se torna ainda mais proeminente, considerando a centralidade que a oralidade ${ }^{18}$ possui nos processos de aprendizagem, distando da dicotomização estabelecida entre a cultura da escrita, típica do universo adulto, e a cultura oral do universo infantil, de modo que a oralidade e a observação se atrelam na aprendizagem do terreiro. Nos cultos afro-brasileiros:

O aprendizado é produto da vivência e de um processo iniciático que se concretiza através da transmissão oral do saber. [...] Aprender a cantar corretamente, dançar bem e pronunciar com precisão as diferentes saudações dirigidas aos mais velhos e aos orixás é o trabalho a que se submetem os que pretendem conhecer e vivenciar a religião dos deuses africanos. (Barros, 2001, p. 96)

A tais questões agrega-se a importância do tempo que é refletida na forma como as crianças aprendem tanto em espaços formais de educação, quanto no terreiro. Elas são ensinadas por etapas. Um terreiro preza por passar seus conhecimentos a quem se mostra ativo nos afazeres da comunidade e possui tempo suficiente para passar de fase de aprendizado, o que não necessariamente segue uma ordem cronológica, no sentido em que se pode encontrar crianças portadoras de um saber sobre o terreiro que em muito ultrapassa aquele possuído por adeptos adultos, como pode verificar-se também em outras pesquisas, como a de Falcão (2010).

É tradicional no Candomblé estimar e muito a senioridade (Prandi, 2001). Exemplo disso é a tradição de outorgar direitos de patente na casa aos iniciados que já possuem sete anos de raspados. Com os sete anos, o indivíduo passa do grau de vodunsi/iyawô para o de egbômi (mais velho). Sendo homem, o egbômi chama-se babatemí, e mulher, iyatemí, contudo, pode-se ter casos de membros recém-iniciados que 
sabem menos que as crianças sobre a dinâmica do terreiro, o que cria uma situação paradoxal com relação à tradição estabelecida.

Vale a pena destacar aqui que o processo de aprendizagem se realiza numa dimensão essencialmente comunitária, a observação e aprendizagem dos ritos, dos saberes do candomblé, não ocorrem apenas numa dimensão individual, mas também, e poder-se-ia mesmo dizer que principalmente, no seio da coletividade, não olvidando, contudo, que tal comunidade é complexa e heterogênea, havendo na mesma uma cultura própria das crianças.

\section{Com Quem Aprendem}

Um sinal de chamada ${ }^{19}$ é o primeiro passo para que os filhos de santo cheguem a alguma atividade ritual. Atendendo ao chamado, eles se posicionam, cada um segundo seu encargo funcional e tempo na religião, ao redor do lócus ${ }^{20}$ da atividade.

Quem chama para os rituais internos e festejos públicos é, hierarquicamente, o pai de santo ou a mãe de santo que zela pela casa (chefe do terreiro $^{21}$ ), os ogãs ${ }^{22}$ (chefes que tocam atabaques), a mãe pequena ou o pai-pequeno (porta-voz da chefia zeladora da casa), as ekédjis (auxiliares do zelador(a) e das divindades no culto) e demais autoridades patenteadas na casa de Candomblé, segundo sua senioridade, que são chamadas de egbômis.

Os pais de santo ou as mães de santo foram iyawôs um dia, isto quer dizer que são "virantes", pois manifestam o transe da divindade. Para chegar a este posto, é necessário que já tenham mais de sete anos de iniciados com raspagem da cabeça. Os ogãs e ekédjis não entram em transe e são escolhidos como chefias auxiliares justamente por este aspecto - eles recepcionarão a divindade enquanto o pai de santo ou a mãe de santo estiverem em transe e falarão por eles e pela divindade em terra.

Rituais como sacrifícios de animais, oferendas de pratos com as comidas preferidas pelas divindades, o trato para com os objetos que são utilizados no culto, iniciações, ou mesmo reuniões de desenvolvimento mediúnico são encabeçadas por essas hierarquias nos locais onde os rituais são executados. Nesses momentos, todos os gestos da 
chefia do terreiro são observados pelos membros, incluindo as crianças, com a tentativa de serem entendidos, compreendidos e de forma prática assimilados.

Como já foi dito, com a finalidade de entender a ritualística, compreender sua funcionalidade e assimilar sua prática por meio do aprendizado observacional é que adultos e crianças participam dos rituais. Portanto, na realidade do terreiro, adultos e crianças são postos em processo de aprendizagem. A distração, a dispersão, os cochichos e as brincadeiras são mal vistos nesses momentos. Durante os rituais, o zelador que chefia a casa sempre cobra atenção, silêncio, respeito e reverência aos demais, dizendo frases do tipo "isso aqui é coisa séria, viu?". Os pais e os responsáveis das crianças reiteram essas cobranças, apoiam a posição da chefia e reforçam nos filhos o comportamento requerido para que também aprendam e compreendam a ritualística. Todavia, a distinção entre o sério e o lúdico é algo por vezes alheio ao universo simbólico da criança, e a brincadeira se mostra como um importante instrumento de aprender o que é sério para elas, uma vez que as crianças relacionam o brincar e o "faz de conta" com as concepções do mundo adulto.

Esta articulação permite às crianças apropriarem-se de aspectos da cultura dos adultos que depois usam, refinam e expandem. [...] As crianças alargam a cultura de pares e contribuem para reprodução do mundo adulto. (CORSARO, 2002, p. 118-119)

No cotidiano, essas crianças disseram que cantam as cantigas que aprendem no terreiro. Tanto cantam, como dançam, dentro e fora do terreiro nos espaços de suas vivências cotidianas. Às vezes cantam apenas trechos, juntos ou acompanhados, outras vezes ficam cantarolando - algumas vezes são corrigidos por estarem cantando "errado", mas sempre com propriedade de quem sabe fazer o que está fazendo - e são ensinados uns aos outros sobre o que significam essas cantigas e para que momentos/divindades são entoadas.

Frequentemente, os filhos de santo se comunicam com as palavras da(s) língua(s) falada(s) no terreiro. Há terreiros nos quais os membros se comunicam perfeitamente nas três matrizes linguísticas 
já citadas: o iorubá do Ketu, o fongbé do Jeje e o quimbundo do Angola. Dessa forma, vão expressando na prática e gradativamente a assimilação que fazem do sentido das linguagens dos rituais e do transe através da imitação dele e das danças.

Algumas tensões observadas no âmbito da aprendizagem dizem respeito à disseminação dos conhecimentos sobre o axé por meios digitais e são práticas rapidamente censuradas pelos zeladores dos cultos de candomblé quando dizem "candomblé se aprende no terreiro e não na internet" - frase ouvida unanimemente da boca dos zeladores e zeladoras a torto e à direita. Esse processo de socialização dos saberes dos terreiros, da forma como tem acontecido na relação transmissão -assimilação com rejeição às rupturas, tem motivado recentemente pesquisas que investiguem como se dá sua relação com o que é (re) produzido na escola.

\section{Entre Comidas, Danças e Santos: algumas interpretações das crianças}

A aprendizagem, pelo que se percebeu, é gradual, ainda que não seja linear, e no caso do vivenciado pelas crianças, isso se dá através da produção de significados próprios. Ao entrevistar Y, notou-se em suas respostas que nem de tudo ela sabia, mas ela explicitou que aquilo que sabia pretendia levar adiante:

Entrevistador - Você vê o pai de santo fazer os rituais de oferenda e matança?

$\mathbf{Y}-$ Às vezes sim.

E - E durante estes rituais, você vê o pai de santo utilizar que materiais nas oferendas e matanças?

$\mathbf{Y}$ - Dendê, mel, azeite e vinho, água e... e outras coisas.

$\mathrm{E}-\mathrm{E}$ o que você aprende sobre estes materiais?

$\mathbf{Y}-E ́ \ldots . . t s c . . . e u$ aprendo que é o que os orixás gosta que utilize com eles.

E - Você sabe o que eles significam?

$\mathbf{Y}$ - Muito não, só algumas coisas.

E - E quais são as coisas que você sabe o que significam? 
$\mathbf{Y}$ - Eu sei que... tsc... que água é vida pra o orixá e pra nós também. Porque é, q... sem a água ninguém...é... ninguém podia fazer nenhuma matança e nenhum ritual.

\section{E. - Quem ensina os significados deles?}

$\mathbf{Y}$ - A mãe-pequena da casa.

Segundo Y, a mãe-pequena da casa é quem ensina sobre os elementos do culto. Ela aprende mais com a mãe-pequena (iyá-kekeré), que além de deter esse cargo, detém também o cargo de mãe-de-cria, ou mãe-criadeira (iyá-ajibonã), e exerce a função de cozinheira das divindades (iyabassé). Sobre isso, Lúcio Conceição (2006, p. 25-26) assinala que

As sacerdotisas dos terreiros, de posse do poder que lhes foi instituído (mesmo nos terreiros regidos por Pais-desanto, as mulheres têm papel destacado na hierarquia sacerdotal: a Mãe-pequena, a Mãe-criadeira, a Ekedi, a Iyá Bassé, e tantos outros cargos que lidam diretamente com a aprendizagem dos iniciados), inserirão estes elementos no bojo desta pedagogia, sem deixar de incorporar os elementos do dinamismo patriarcal dominante, ainda que de forma reinterpretada. O dinamismo matriarcal marcará profundamente a pedagogia hora estudada.

De certo que ao poder feminino é dada, tradicionalmente, a atribuição de guiar pelo caminho/orientar. O autor defende com isso que existe uma "Pedagogia" no Candomblé

[...] vivenciada, em alguns casos, de forma mais tensa pelos iniciantes, ao trazerem diferentes perspectivas que conflitam com o processo de aprendizagem necessário para construção da pertença a este lugar; mas também por aqueles membros mais antigos, que enfrentam os desafios de preservar valores e ensinamentos de seus ancestrais, os quais alicerçam esta pedagogia e que na sociedade tornaram-se secundários. São conflitos que apontam diferenças entre o modelo pedagógico dominante na sociedade e a Pedagogia presente no culto aos orixás (Conceição, 2006, p. 12)

Sobre a preservação das tradições originárias e as poucas rupturas, esse autor verificou no terreiro onde pesquisava um indício de conti- 
nuidade, de descendência, de aprendizado que permaneceu imutável, o que é bastante questionável, uma vez que se pode falar sim em uma história própria de cada casa e não em uma pureza ritualística (Ferretti, 1995), já que a própria tradição é dinâmica. O que pode parecer uma visão empobrecida (Rabelo, 2008) sobre a educação executada nos terreiros, na verdade é uma visão sem a compreensão de que as rupturas, as tensões, os conflitos e as descontinuidades no ambiente do terreiro existem em menor quantidade e acontecem em menor velocidade do que nos espaços formais de educação e até mesmo na sociedade fora do terreiro, sendo assim não tão aparentes (Rabelo, 2008, p. 177), haja vista a cumplicidade - exigida para se tornar filho de santo - para com a preservação do esqueleto (Oliveira, 2008) tradicional da religião.

Nisso, Leite (2006, p. 34) aponta que “[...] no Candomblé há uma certa uniformidade de comportamento e de visão de mundo de seus componentes. Tem que haver, par que possa existir a continuidade e legitimação do sistema religioso social e cultural do Candomblé", confirmando que é preciso se sujeitar a uma negação do que já foi aprendido e internalizado de uma cultura religiosa anterior para poder então entender, na conversão, os elementos religiosos afro brasileiros.

Sendo um aprendizado gradual, sentido e praticável, é possível encontrar nas respostas de W à entrevista o "inexplicável" e o "aprendendo de pouquinho em pouquinho". O conhecimento de W sobre o axé era afirmado como pouco devido à sua iniciação com raspagem ainda não ter acontecido, contudo, o que é aprender muito ou pouco é relativo, pois é sempre em relação a alguém, a um grupo, normalmente o grupo do adulto, portanto, a percepção da própria aprendizagem é sempre um exercício de alteridade.

Contudo, em sociedades como a nossa, a alteridade da infância está em relação direta com o mundo adulto; e, em muitos momentos, o mundo de uma e o de outro, ainda que se toquem e se cruzem, permanecem separados, não permitindo compreender a natureza política que os constitui como sujeitos em relação. (Gusmão, 2012, p. 168)

Então, a W restava saber somente aquilo que as pessoas raspadas, digamos inseridas de cabeça no ritual de iniciação, poderiam passar-lhe como informações sobre o axé: 
Entrevistador - Você vê o pai de santo fazer os rituais de oferenda e matança?

$\mathbf{W}-\operatorname{Sim}$.

E - Durante esses rituais, você vê o pai de santo utilizar que materiais nas oferendas e matanças?

$\mathbf{W}$ - Eu vejo ele utilizando um monte de materiais.

E - E o que você aprende sobre esses materiais?

W - Não sei, é inexplicável.

E - Você sabe o que eles significam?

W-Mais ou menos.

E - Por que mais ou menos?

W - Porque eu vou aprendendo de pouquinho em pouquinho.

E - Quem ensina os significados deles?

W - O pai de santo, a minha mãe.

E - E você pretende seguir como ele tem ensinado?

$\mathbf{W}$ - Pretendo.

Caputo e Passos (2007, p. 99) afirmaram que José Beniste disse a elas que no candomblé "[...] o conhecimento das coisas do santo é passado na medida em que haja participação, pois tudo se aprende fazendo. Não há uma cultura didática, há uma cultura de imitação. Viu, repetiu, aprendeu". Portanto, W se percebe como não sabendo muito porque não é raspada.

Saber é um sinal de iniciação e "este que sabe" é alguém já integrado ao grupo e à cultura. O segredo significa a sua pertença ao grupo. Ser iniciado é ter acesso ao segredo e fazer parte do grupo. É mais, é passar a pertencer a uma nova família, a "família de santo". (Caputo; Passos, 2007, p. 97)

O religioso afirmará que, para pertencer ao axé, é preciso ter sido integrado a ele. Daí dizer que "é do axé de fulano", "descende do axé de sicrano", "agora está no axé de outro pai de santo" quando se fala da integração dos sujeitos aos ilês, isto é, aos terreiros. Leite (2006, p. 30) chega a afirmar que "[...] um Ilê também é uma escola, onde os 
iniciados aprendem a conviver na irmandade e solidariedade, aprendendo e vivenciando uma religião que não tem o registro escrito e sim a oralidade e o aprender fazendo". Mãe Beata, contando à Stela Caputo e à Mailsa Passos (2007, p. 95), já dizia que em qualquer fase da vida se vive aprendendo o candomblé. Noam, neto de Mãe Beata, contou a essas autoras (Caputo; Passos, 2007, p. 96) que aprende errando. "Quando a gente erra é bom porque vem alguém e diz como é. Aí a gente repete e dança certo, canta do jeito certo. Mas também se não tiver pé de dança não adianta que não vai fazer direito nunca". Aliando pé de dança a fazer direito, pode-se confirmar que se exige uma disposição e um comportamento de cumplicidade para a reprodução ideal de assimilação.

O pé de dança pode denotar um modo próprio, mas aqui é interpretado como disposição, e o fazer direito é um modo reproduzido que, obviamente após ser transmitido, é assimilado e repetido. Para Campos (2009, p. 150),

[...] as pesquisas sobre religião, muitas vezes com forte enfoque institucional, tendem, em geral, a abordar os adultos, e dentro destes os líderes e membros com maior tempo de conversão por estes serem os portadores do conhecimento sagrado reconhecidos socialmente.

No entanto, as crianças produzem uma interpretação particular do sagrado, do seu significado e de como se aprende sobre ele.

\section{Aprender Por Que e Para Quê?}

Há no terreiro a figura do(a) tutor(a) que ensina à tutela seu modo de enxergar e compreender o mundo, como se portar em casa e fora de casa, as atividades que devem ser desempenhadas no lar e, assim, espera-se das crianças que o(a) auxiliem, equilibrando os momentos de lazer, brincadeiras e diversão a estas horas de integração ao universo das responsabilidades adultas, divisão essa aparentemente artificial produzida a partir da leitura dos adultos sobre essa realidade cultural.

Nas entrevistas, estão registradas falas que demonstram a preocupação das crianças em relação ao saber também fora do terreiro. 
O mundo do saber está interligado ao mundo do trabalho e, com isso, uma carreira profissional bem-sucedida se mostra, na maioria das vezes, dependente de um sucesso escolar/acadêmico.

Vejamos a seguir alguns trechos com respostas de W. e Y. ao serem questionadas sobre seus aprendizados:

[ ...]

Entrevistador - E o que é que você aprende no terreiro?

$\mathbf{W}-A h$, eu aprendo várias coisas. É, um exemplo, deixa eu pensar...eu aprendo que deve cuidar, não se descuidar, que você tem que obedecer, normal. Igual uma pessoa normal.

E - Você tem que cuidar de quê?

W - Ah, eu não cuido de nada, né? Por enquanto. Mas eu vejo as pessoas cuidando do santo. Eu acho bonito demais isso.

E - E você gosta do que você aprende nesse espaço?

W-Sim. É inexplicável.

E - E com quem é que você aprende?

$\mathbf{W}$ - Eu aprendo olhando. E... e com a minha mãe também.

$\mathrm{E}$ - E o que você aprende aqui você usa em outro lugar?

$\mathbf{W}-$ Às vezes sim e às vezes não.

$\mathrm{E}$ - $\mathrm{O}$ que você aprende aqui você usa na escola?

W - Não. Porque não dá pra usar.

E - Por quê?

W - Porque as coisas daqui é muito diferente da escola.

$\mathrm{E}-\mathrm{E}$ o que os seus pais dizem sobre o terreiro?

$\mathbf{W}$ - Ah, eles dizem a mesma coisa que eu, que é ótimo, que... é bom. É isso.

E - E o que é a escola pra você?

W - Ah, a escola éo meu futuro melhor. Meu sonho é ser médica, então meu pai disse que siga a escola que um dia eu posso chegar lá.

$\mathrm{E}$ - E o que é que você aprende na escola?

$\mathbf{W}$ - Ah, na escola eu aprendo ler, escrever, fazer contas, várias coisas. E aprendo a ter educação.

E - E você gosta da escola? Por quê? 
W - Porque lá eu aprendo várias coisas. Lá eu aprendo a... fazer matemática, ciências, um bocado de coisas.

$[\ldots]$

E - E você pretende terminar os estudos na escola?

W - Sim, pretendo, pra ter um futuro melhor. Meu sonho é ser modelo ou médica.

E - E o que você pretende fazer depois que terminar os estudos na escola?

W - Eu pretendo fazer faculdade e seguir meu sonho.

$[\ldots]$

\section{Entrevistador - E como é o seu dia a dia no terreiro?}

Y - Meu dia a dia no terreiro é... tsc... eu acho legal que a gente... a gente vai aprendendo... cada dia a gente vai aprendendo mais coisa que a nossa mãe ensina.

\section{E - E por que você vai à escola?}

$\mathbf{Y}$ - Porque eu tenho... tenho que aprender muitas coisas que... que pra eu chegar no meu futuro, pra poder trabalhar eu preciso ter tods... todas as minhas série completa.

\section{E - E você gosta da escola?}

$\mathbf{Y}$ - Gosto. Eu só acho ruim de vez em quando porque algumas pessoas são muito preconceituosas.

\section{E - E como é o seu dia a dia na escola?}

$\mathbf{Y}$ - Tsc é... assim... eu... tem hora que as pessoas me perguntam minha religião, eu falo. Algumas... algumas acha tudo bem e outras fica criticando. Ai tem hora que... tsc... que às vezes eu preciso até ir na diretoria. Então, eu acho assim, que isso é chato, né?

\section{E - E o que você espera da escola?}

$\mathbf{Y}$ - Eu espero que as pessoas tomem uma providencias pra acabar o preconceito. Porque eu não vejo nenhum professor falar sobre isso.

\section{E - E o que a escola pode fazer para a sua vida?}

$\mathbf{Y}$ - (Suspiro) Pode fazer muitas coisas. Pode tsc... é... até me realizar ni... ni uma famosa. É porque... ser... eu não vou ter nenhuma profissão se eu não estudar.

\section{E - Do você não gosta na escola?}


$\mathbf{Y}$ - Eu não gosto... é dos preconceito e porque às vezes as pessoas lá zoam muito das pessoas por causa da religião, cor, essas coisas...

\section{E - E o que você mais gosta de fazer na escola?}

Y - O que eu meu gó... o que eu mais gosto de fazer é quando chega a hora de ler na matéria História.

\section{E - E por que História?}

Y - Porque eu acho que assim... também fala... também fala sobre o Candomblé às vezes.

\section{E - E você gosta dos professores?}

Y - Gosto... eu gosto deles. Eles são legais. O que eu não gosto só é porque... porque nenhum pro... nenhum professor fala de prec... de preconceito. Então eu acho que isso nunca vai acabar se ninguém tomar uma providência.

\section{E - Você pretende terminar os estudos na escola? Por quê?}

Y - Sim, porque eu acho que... que... é... pra eu conseguir um trabalho eu preciso de todos os... os estudos. Então, mas é eu... eu não pretendo sair da escola enquanto eu não terminar os meus estudos.

E - E o que você pretende fazer depois que terminar os estudos na escola?

$\mathbf{Y}-$ Eu pretendo ser nutricionista.

$\mathrm{E}$ - Como é que você aprende as coisas no terreiro?

Y - Porque a mãe pequena da casa ensina tudo.

$\mathrm{E}$ - E você gosta de aprender nesse espaço?

$\mathbf{Y}$ - Gosto. Amo.

E - O que você aprende aqui você usa em outro lugar?

$\mathbf{Y}$ - Às vezes sim. À... Às vezes eu... as palavras que ela me ensina em iorubá, às vezes eu falo em outros lugares também.

$\mathrm{E}$ - E você usa o que você aprende aqui na escola?

$\mathbf{Y}-$ Na escola? É, uso.

$\mathrm{E}-\mathrm{E}$ o que é a escola pra você?

Y - A escola é um lugar que... que pra eu chegar no meu futuro eu preciso dela.

E - E o que é que os seus pais dizem sobre a escola? 
$\mathbf{Y}$ - Dizem que... que é bom, que é boa a escola, que vai $f \ldots$ éf...éf...é bom pra mim, que... que sem ela... sem ela eu não sei... eu não sou nada no meu futuro. Esses tipos de coisas.

Como se pode perceber, foi necessário fazer mais perguntas à Y, porque ela abrangia suas respostas que, por sua vez, demandavam mais perguntas. As respostas de $\mathrm{W}$ foram muito centradas, fechadas e finais.

As coisas "diferente da escola", como W disse, podem ser interpretadas como saberes inutilizados devido à desvalorização das vivências e experiências que estas crianças vão aprimorando na(s) cultura(s) fora da escola (a do terreiro neste caso). Mesmo assim, essas crianças depositam suas esperanças na escola quando dizem que ela é um "futuro melhor", o que não é nosso foco nesse artigo, no qual nos delimitamos mais sua relação com o que é aprendido no terreiro e na escola que aos percursos que venham seguir nesses dois espaços de formação.

Y fez questão de deixar claro o quanto valoriza os aprendizados escolares. Para ela, os aprendizados na escola a garantirão um futuro com trabalho, uma profissão que a dignifique como agente ativa de sua sociedade. Além de futuro profissional, Y falou de religião e de cor. Apesar de ter a pele branca, Y diz que sofre preconceito por professar uma religião estigmatizada. O que as entrevistas apontam é a necessidade de aprender para um futuro profissional e aprender em outro para um futuro religioso, ainda que sejam aprendizados dialógicos marcados por tensões, percebeu-se nas falas, quando se referem à escola, que existe um processo antagônico mais do que contraditório da parte docente: um processo antipedagógico.

Apesar da relevância atribuída ao espaço escolar por parte das crianças há de se ressaltar que tal espaço é compreendido muitas vezes como um lugar de negação de sua identidade religiosa, como nos aponta a pesquisa de Sousa (2010, p. 57):

Uma das perguntas que fiz a erê de Ewá foi sobre a relação professor/aluno e ela não me falou muito, apenas silenciou-se. Mas, disse que não pode contar para a professora e os colegas da escola que é de candomblé. Segundo ela, não poderia contar a eles porque eles deixariam de gostar dela. 
Esse processo de silenciamento dos sujeitos relaciona-se diretamente com os aspectos conservadores da instituição escolar, que valoriza uma dada realidade cultural em detrimento de outras, o que é operacionalizado principalmente por meio de determinados agentes, no caso os professores. Na pesquisa de Caputo (2012, p. 204), o que chama a atenção a perspectiva assumida pelos docentes com relação ao Candomblé. Segundo a autora:

Dos 14 professores, nove responderam que nunca pensaram sobre crianças no candomblé porque não acreditam que existam crianças que frequentam ou pratiquem candomblé na escola. Uma das entrevistadas afirmou: "Não temos crianças com esse 'problema' aqui na escola, a maioria é católica." Cinco professores afirmaram que acham "um absurdo" que crianças pratiquem o candomblé. "As crianças não devem ser induzidas à macumba só porque os pais frequentam", respondeu uma professora. Perguntei a essa professora se os pais católicos também não "induziam" seus filhos ao catolicismo quando os batizavam, levavam às missas, colocavam no catecismo para a Primeira Comunhão etc. A professora respondeu: "Mas o catolicismo não é coisa do diabo, é a religião normal. (Caputo, 2012, p. 204)

Tal postura existente na escola leva à construção de um sentimento ambivalente com relação a esse lugar, pois, por um lado essas crianças são socializadas de uma tal forma que o compreendem como relevante para a sua formação, tendo em vista o processo paulatino e crescente de escolarização entre os praticantes do Candomblé (Duccini, 2005), por outro é percebido como um lócus de negação de sua própria identidade.

\section{E a Escola?}

Detendo-se, de um modo geral, sobre as propriedades culturais da escola, acertando neste artigo que, numa passagem bem rápida e levada pelas falas das crianças, se está discorrendo não sobre seu espaço físico, mas sim sobre um ambiente de vivências a partir da ótica nativa. Que diálogos a escola mantém com o que é aprendido em outros 
espaços de formação dos sujeitos? Como as crianças articulam o que é vivenciado no terreiro e na escola?

Há uma troca de experiências, uma socialização de saberes, uma sociabilidade - o que não quer dizer que na formatação atual da escola ele seja uma prática efetivada pelas políticas educacionais do planejamento pedagógico da maioria das escolas públicas e privadas brasileiras.

Na cultura de pares do universo infantil escolar (CORSARO, 1997), os "eus" que interagem nas atividades do lazer produzem e são produtos de aprendizados diferentes estruturados por sujeitos com experiências diversas. Essa relação poderia e deve valorizar os saberes que as crianças trazem de suas experiências em outros espaços de formação. O problema que se percebe é que, como coloca Sarmento (2011), a escola se ocupa com o aluno e não com a criança.

De algum modo, perante a instituição, a criança "morre", enquanto sujeito concreto, com saberes e emoções, aspirações, sentimentos e vontades próprias, para dar lugar ao aprendiz, destinatário da acção adulta, agente de comportamentos prescritos, pelo qual é avaliado, premiado ou sancionado. A escola criou uma relação particular com o saber, uniformizando o modo de aquisição e transmissão do conhecimento, para além de toda a diferença individual, de classe ou de pertença cultural. (Sarmento, 2011, p. 588)

A escola potencialmente poderia, assim, estabelecer uma relação entre o "eu empírico" e o "eu epistêmico" destas crianças (Charlot, 2005 ) - uma relação entrelaçada multicultural e interculturalmente (Candau; Leite, 2007) pelas suas experiências individuais e de grupo; Contudo, na realidade empírica o que encontramos é a incorporação de um "arbitrário cultural" nos termos postos por Pierre Bourdieu e Jean-Claude Passeron (2009). A escola, em todo seu processo marcadamente contraditório de exclusão e inclusão, abriga alunos com culturas diversificadas (Sacristán, 2005) para padronizar pela afirmação da cultura dominante23. Sendo assim, a vivência no terreiro tende a ficar "fora da escola", já que a escola historicamente ignora os valores culturais negros. (Machado, 2002) 
Em uma conversa com uma das crianças, fora perguntado se a professora da turma dela e os outros alunos sabiam que ela a família eram de Candomblé. Ela respondeu que não sabia. "Você também nunca fez questão de dizer?", perguntei. "Não. Tô nem aí!", respondeu a criança, dizendo logo mais "[...] contando que eles gostem ou não, quem tem que gostar sou eu". Apesar de o juízo de gosto aparecer nessa colocação da criança, o fato da invisibilidade estar presente indica muitas coisas. Uma delas seria a não preocupação com a prática de assumir identidades, relegando a importância dela em espaços coletivos.

Chama a atenção o fato de que na escola é recorrente o caso de preconceito sofrido por crianças que são do candomblé, como em acontecimento recente noticiado pelo Jornal Extra, em janeiro de 2009, no qual o aluno foi expulso da escola e chamado de filho do demônio. Esse cenário liga-se diretamente a uma questão mais ampla, que diz respeito à intolerância religiosa, na pesquisa de Bakke (2011) observouse que raramente os professores discutem de forma mais detalhada a questão das religiões afro-brasileiras, mesmo quando se propõem a debater sobre a história e a cultura afro-brasileiras, todavia, no único caso observado durante seu trabalho de campo em que uma professora se propôs a trabalhar de forma mais detalhada essa questão em sala de aula, houve protestos por parte daqueles que se disseram desrespeitados pela menção às religiões afro-brasileiras no espaço escolar.

\section{Considerações Finais}

Buscou-se, ao longo deste artigo, trazer uma contribuição para a discussão que se desenvolve na interface entre a Antropologia e a Educação, lançando mão também de leituras no campo da Antropologia da Criança e da Religião, tendo como norte em nossa pesquisa a indissociabilidade entre teoria e método.

O que se pode verificar, por meio da etnografia e das entrevistas, aponta para duas questões principais: a) no terreiro há claramente um processo de aprendizagem no qual as crianças se engajam, e no qual, muitas vezes, há desencontros em torno deste com relação à perspectiva do mundo adulto e do mundo da criança (em especial no que tange ao lugar que as brincadeiras ocupam nesse processo, pois o que 
pareceu é que para os adultos a brincadeira durante o culto atrapalha a aprendizagem) - contrariamente, percebeu-se que a brincadeira é constitutiva da aprendizagem, ou melhor dizendo, é talvez o principal meio dessa aprendizagem, que envolve inúmeros elementos marcadores das identidades dos sujeitos; b) quando fora indagado às crianças sobre a aprendizagem no universo escolar, o que se percebeu foi uma separação entre a escola e o mundo da criança (no caso refere-se ao terreiro), o que parece ser articulado pelas crianças de forma inventiva, por mais que percebam a existência de preconceito por parte de outros agentes devido a seu pertencimento religioso, uma vez que claramente entendem a necessidade de se valorizar tanto os conhecimentos escolares como os não escolares.

Espera-se que essa reflexão aqui trazida possa contribuir de algum modo para a discussão sobre a relação entre identidade e educação, pois, compreender os processos de aprendizagem e a relação estabelecida entre o terreiro e a escola não é algo que diz respeito apenas às crianças de Candomblé. Iniciativas como a Lei n. 10.639/2003 certamente demarcam avanços importantes nas discussões sobre os dilemas culturais em nossa sociedade e como se apresentam na realidade escolar, contudo, ainda há muito que avançar, e, para tanto, é condição sine qua non reconhecer que muitas das questões postas neste cenário não são apenas pedagógicas, mas sim antropológicas, na medida em que remetem diretamente à problemática da alteridade.

Fica evidente que o silenciamento das crenças perdura por questões protetivas, pelas quais os religiosos, sendo crianças ou adultos, temerários de retaliação social, chegam até a negar que pratiquem o candomblé.

\section{Notas}

1 Doutor em Sociologia pela Universidade Federal de Pernambuco (UFPE), Professor da Universidade Federal de Santa Catarina (UFSC) e colaborador do Programa de Pós-Graduação em Educação da Universidade Federal de Alagoas (UFAL).

2 Mestrando em Educação pela Universidade Federal de Alagoas (UFAL), Bolsista da Fundação de Amparo à Pesquisa do Estado de Alagoas (FAPEAL).

3 Candomblé é o nome da religião de matriz africana reformulada nas terras brasileiras que reúne diferentes formas de cultuar as divindades ancestrais africanas. Será utilizada neste artigo a palavra candomblé, com inicial minúscula, quando se 
referir ao culto de forma especificamente ritual, e com inicial maiúscula quando se referir à religião do Candomblé de forma geral.

4 Utiliza-se tanto a palavra santo, quanto a palavra divindade para se referir às divindades ancestrais das mais variadas origens étnicas africanas. Para os povos de origem iorubá, as divindades ancestrais, isto é, os santos, são chamados de orixás. Para os povos de origem daomena, as divindades são os voduns - espíritos da Natureza. Já para os povos de origem banto, os santos são os minkisi - plural de nkisi (pronuncia-se inquice). Cada santo tem sua relação de filiação com os devotos, explícita nas características psicossomáticas e nos arquétipos psicológicos (o mesmo que dizer que o filho puxa ao pai).

5 A raspagem da cabeça é um ritual de origem iorubá incorporado às culturas de voduns desde o território africano, devido às práticas interculturais já registradas antes da vinda dos africanos ao Novo Mundo. No Brasil, a obrigatoriedade de raspar a cabeça para se consolidar como filho de santo com laços de parentesco estabelecidos na casa se dá porque a iniciação é vista como um nascimento para uma nova vida, dessa vez dedicada às coisas do santo do iniciando e dos santos da casa. A crença de que o recém-nascido tende a vir ao mundo sem cabelos e, conforme seu crescimento, vão nascendo seus pelos é uma forma e explicar a prática. Outra forma se dá na crença do plantio do axé: a cabeça é vista como um território a ser lavrado e, ao seu centro, são plantadas substâncias mágicas próprias do santo ao qual se está iniciando. Várias explicações simbólicas integram a prática da raspagem da cabeça. (Bastide, 2001)

6 Trata-se de uma pesquisa em curso ainda, devido a tanto utiliza-se também de dados referentes a outras pesquisas etnográficas sobre essa temática visando embasar nossos argumentos.

7 Entende-se aqui aprendizagem nos termos propostos por Ingold (2000), ou seja, como enculturação, que se refere à aquisição de ideias, regras ou esquemas cognitivos.

8 Sobre Oxum e demais divindades do Candomblé, ver Bastide (1985).

9 Segundo Bastide (2001, p. 308) "Axé: este termo corresponde mais ou menos ao que os sociólogos chamam mana e é sempre empregado, não para designar uma força impessoal, mas para certas espécies de encarnação de forças (ervas, alicerces do candomblé etc.)".

${ }^{10}$ A casa de axé foi inaugurada em 1979 no bairro de Bebedouro, reinaugurada no bairro atual em 1999 e teve seu axé reinaugurado em outra casa do mesmo bairro em 2007.

${ }^{11}$ A palavra erê significa "encanto". O(a) erê é uma entidade infantil que se apresenta logo após a divindade, podendo ser menino ou menina independentemente do gênero da divindade. Há erês com comportamento intergênero.

12 As iniciações podem ser feitas individualmente, ou a um grupo de iniciandos a divindades tanto semelhantes, quanto distintas. Quando a iniciação é coletiva, chama-se a esse grupo de barco de iyawôs ou áhàma.

13 A palavra ebó, do iorubá, significa sacrifício de culto. O sufixo bó deriva de obó/ umbó, que significa adoração. Exemplo: a palavra borí é a contração de ebó orí, culto/sacrifício/adoração à cabeça.

14 Exemplos de palavras e frases em iorubá: ení (esteira), afomon (homem doente), omí (água), obá (rei), ayê (mundo), ilé (terra), ilê (casa), ijí (árvore), irê (felicidade), Ê kaarô! (Bom dia!), inã (fogo), ará (raio), Ôku abó! (Seja bem-vindo!), Agô! (Com licença!), orunkó mi odara (meu nome é bonito). Exemplos de palavras e 
frases em fongbé: azan (esteira), azonce (homem doente), ezin (água), ahossú (rei), ahóssi (rainha), ayí (terra), atin (árvore), adan (corajoso), izó (fogo), Dadá Segbô ê ná txé nú wê! (Deus te abençõe!), ún dó gbé nú wê! (eu te saúdo/invoco!). Exemplos de palavras e frases em quimbundo: dixisa (esteira), dilonga (prato), amazi (água), maionga (banho), Nzambiapongo no akuateçá! (Deus te proteja!), makuiú no Nzambi! (a mão de Deus esteja sobre ti!), dijina wane (nos diga seu nome).

15 Os povos africanos, em suas distintas culturas étnicas, têm diferentes maneiras para explicar o surgimento do universo. Um exemplo é que, para os iorubás, tudo o que existe surgiu do hálito do Deus Supremo (Olodumarê), se opondo à teoria criacionista cristã. Um exemplo de visão de mundo é mostrado nos mitos que explicam as chuvas, colocando a divindade Oxumarê como responsável por transformar a água dos rios em nuvem, levando-a aos céus por meio da evaporação e fazendo aparecer o arco-íris como símbolo de mudança climática.

${ }^{16}$ As divindades executam mímicas dançadas, contando através delas sua história e suas funções. Os gestos e os movimentos dançados são interpretados como funcionalidades dos deuses.

17 Durante a fase final da iniciação iorubá ao orixá Xangô, registrada por Pierre Verger na África, a Iyá Xangô adverte os iniciados sobre casos de acidentes e casos que necessitam de vingança, dentre outras pertinências da vida cotidiana. "Se alguém te der um pontapé, te puxar as orelhas ou te der pancadas na testa, por descuido ou acidente, não precisas dizer nada, mas se exagerar e o fizer de propósito, é preciso que te vingues". (Verger, 2002, p. 31)

18 O Candomblé mantém sua tradição oral de passar seus costumes e ritos aos iniciados na religião, ainda que haja mudanças em curso com relação a essa questão.

${ }^{19}$ O sinal de chamada é o barulho ocasionado pelo balanço do adjá. O adjá, ou adjarim, é uma sineta de metal com duas ou mais bocas utilizada para invocar os filhos de santo para alguma atividade, bem como a seus santos. Diz-se que o adjá tem o poder de acordar uma divindade em alguém. O adjá que possui duas bocas é usado unicamente para chamar os santos aborós (masculinos). O adjá que possui três ou mais bocas é usado para chamar tanto santos masculinos, quanto femininos (iyabás), andróginos, hermafroditas e de gênero alternados. Outra forma invocatória é o toque do atabaque

${ }^{20}$ Geralmente, a mina é o lócus central da maioria das atividades rituais. A mina da casa está situada ao centro do salão de dança e é onde está plantado o axé da casa. Ela representa a territorialidade do sagrado e os antepassados, pois é a própria Terra onde reside a morte e a vida do mundo, à qual se deve respeito sendo saudada na cantiga “Igbá orixá, igbá Onilé/Onilé, mojubá ô!" (Para saudar orixá, tem que saudar Onilé - Senhora da Terra/A Onilé dirijo meus respeitos).

${ }^{21}$ O chefe do terreiro de Ketu-Nagô é chamado de Babalorixá, onde babá significa "pai". Se a chefia for feminina, chama-se Iyalorixá, onde iyá significa "mãe". Os termos Doté e Doné, são designados, respectivamente, a zeladores e zeladoras dos cultos Jeje Mahí, Jeje Savalu, Jeje Daomé e, em alguns casos, do Jeje Modubí (Bravun). Mejitó é título único para os sacerdotes iniciados para Bessén no Jeje Mahí. Já Tata riá nkisi (ou tatetu) e Mametu riá nkisi são os pais e mães de santo, respectivamente, no Candomblé de Angola.

${ }^{22}$ A origem deste termo é do Candomblé Jeje e foi adotada pelo Ketu-Nagô para se referir aos seus Alabês. No Candomblé de Angola estes chefes são chamados de Kambones ou Xicarangomas. Houve adoção de termos do Jeje pelo Ketu também 
quanto às Ekédjis. No Ketu, as auxiliares são chamadas de Ajoiés, mas como defendido por Nicolau Parés (2007), os cultos aos voduns conferiram uma formatação ritual e espacial modeladora das demais nações de candomblé do Brasil.

23 Sobre a formação de professores e a adoção dessa nova postura pelo corpo docente nas práticas escolares e nos processos educativos, ver Candau (2002), Candau (2003) e Moreira e Candau (2003).

\section{Referências}

ARIÈS, Philippe. História social da criança e da família. Rio de Janeiro: Guanabara, 1981.

AZANHA, José Mário Pires. Uma ideia de pesquisa educacional. São Paulo: Edusp, 1992.

BAKKE, Rachel Rua Baptista. Na escola com os orixás o ensino das religiões afro-brasileiras na aplicação da Lei n. 10.639 2011. Tese (Doutorado em Antropologia) - Faculdade de Filosofia, Letras e Ciências Humanas. Universidade de São Paulo, São Paulo, 2011.

BARROS, José Flávio Pessoa. Xangô. A História que a Escola ainda não Contou. In: VALLA, Victor Vincent. Religião e cultura popular. Rio de Janeiro: DP\&A Editora, 2001, p. 91-112.

BARTH, Fredrik. O guru, o iniciador e outras variações

antropológicas. Rio de Janeiro: Contra Capa Livraria, 2000.

BASTIDE, Roger. O Candomblé da Bahia: rito nagô. São Paulo:

Companhia das Letras, 2001.

. As religiões africanas no Brasil: contribuição a uma sociologia das interpenetrações de civilizações. v. I. 2 ed. São Paulo: Livraria Pioneira Editora/EDUSP, 1985.

BELO, Rafael Alexandre. No rastro do Xangô Alagoano: contribuições para a história da educação. Dissertação (Mestrado em Educação) - Centro de Educação. Universidade Federal de Alagoas. Maceió: 2012.

BOURDIEU, Pierre. Questões de sociologia. Rio de Janeiro: Marco Zero, 1983.

BOURDIEU, Pierre; PASSERON, Jean-Claude. A reprodução: elementos para uma teoria do sistema de ensino. Coleção Recensões LusoSofia Lisboa: Editorial Vega, 2009.

CAMPOS, Roberta Bivar Carneiro. Pesquisando o invisível: percursos metodológicos de uma pesquisa sobre sociabilidade infantil e diversidade religiosa. Teoria \& Sociedade, Belo Horizonte, v. 17, n 1., p. 148-175. 2009. 
CANDAU, Vera Maria Ferrão. Relatório da pesquisa universidade, diversidade cultural e formação de professores. Rio de Janeiro: Departamento de Educação da Pontifícia Universidade Católica do Rio de Janeiro. Rio de Janeiro: 2003.

. Sociedade, cotidiano escolar e cultura(s): uma aproximação.

Educação \& Sociedade. Campinas, v. 23, n. 79. p. 125-161, 2002.

CANDAU, Vera Maria; KOFF, Adélia Maria Nehme Simão. Conversas com... Sobre a didática e a perspectiva multi/intercultural. In: Educação $\boldsymbol{\varepsilon}$ Sociedade, Campinas, v. 27, n. 95. p. 471-493, 2006.

CANDAU, Vera Maria; LEITE, Miriam Soares. A didática na perspectiva multi/intercultural em ação: construindo uma proposta. Cadernos de Pesquisa, São Paulo, v. 37, n. 132., p. 731-758, 2007.

CAPUTO, Stela Guedes. Educação em terreiros e como a escola se relaciona com crianças de candomblé. Rio de Janeiro: Pallas, 2012.

CAPUTO, Stela Guedes; PASSOS, Mailsa. Cultura e conhecimento em terreiros de Candomblé: lendo e conversando com Mãe Beata de Yemonjá. Currículo sem Fronteiras, Porto Alegre, v. 7, n. 2. p. 93-111, 2007.

CHARLOT, Bernard. Relação com o saber, formação dos professores e globalização: questões para a educação hoje. Porto Alegre: Artmed, 2005.

COHN, Clarice. Antropologia da criança. Rio de Janeiro: Jorge Zahar, 2005.

CONCEIÇÃO, Lúcio André Andrade da. A Pedagogia do Candomblé: aprendizagens, ritos e conflitos. Dissertação (Mestrado em Educação) Departamento de Educação. Universidade do Estado da Bahia. Salvador: 2006.

CORSARO, William Arnold. Entrada no campo, aceitação e natureza da participação nos estudos etnográficos com crianças pequenas. Educação \& Sociedade, Campinas, v. 26, n. 91. p. 443-464, 2005.

. A reprodução interpretativa no brincar ao "faz-de-conta" das

crianças. Educação, Sociedades \& Culturas, Porto, n. 17, p. 113-134. 2002.

Press, 1997.

A sociologia da infância. Thousand Oaks (CA): Pine Forge

DAMATTA, R. O ofício de etnólogo, ou como ter Anthropological Blues. In: NUNES, E. A Aventura sociológica: objetividade, paixão, improviso e método na pesquisa social. Rio de Janeiro: Zahar, 1978. p. 23-35. 
DUCCINI, Luciana. Diplomas e decás: re-interpretações e identificação religiosa de membros de classe média do candomblé. Tese (Doutorado em Ciências Sociais ) - Faculdade de Filosofia e Ciências Humanas, Universidade Federal da Bahia, 2005.

DURKHEIM, Émile. Educação e sociologia. Petrópolis: Vozes, 2011.

FALCÃO, Christiane Rocha. Ele já nasceu feito: o lugar da criança no Candomblé. Dissertação de Mestrado em Antropologia pela Universidade Federal de Pernambuco. Recife: 2010.

FERRETTI, Sérgio F. Repensando o sincretismo. São Paulo/São Luís: EDUSP/FAPEMA, 1995.

FONSECA, Eduardo Aquino. As funções e os significados das festas nas religiões afro-brasileiras. Cadernos de Estudos Sociais, Recife, v. 13, n 2, p. 255-276, 1998.

GEERTZ, Clifford. A interpretação das culturas. Rio de Janeiro: LTC, 1989.

GUSMÃO, Neusa Maria. Olhar viajante: antropologia, criança e aprendizagem. Pro-Posições, Campinas, v. 23, n 2, p. 161-178, 2012.

. Os desafios da diversidade na escola. In: GUSMÃO, Neusa Maria.

(Org.). Diversidade, cultura e educação: olhares cruzados. São Paulo: Biruta, 2003, p. 83-105.

INGOLD, Tim. The perception of the environment. London: Routledge, 2000 .

JORNAL O EXTRA. Terça-feira 27 de janeiro de 2009, Ano XI.

LAPLANTINE, François. La description ethnographique. Paris: Armand Colin, 2011.

LEITE, Valderlei Furtado. Candomblé e educação: dos ilês às escolas oficiais de ensino. Dissertação de Mestrado em Educação pela Universidade São Marcos. São Paulo: 2006.

MACEDO, Elizabeth. A cultura e a escola. In: MISKOLCI, Richard. (Org.). Marcas da diferença no ensino escolar. São Carlos: EdUFSCar, 2010. p. $11-44$.

MACHADO, Vanda. Ilê axé: vivências e invenção pedagógica - as crianças do Opô Afonjá. Salvador: Edufba, 2002.

MAGNANI, Jose Guilherme Cantor. Etnografia como prática e experiência. Horizontes Antropológicos, Porto Alegre, v. 15, n. 32, p. 129-156, 2009.

MOTTA, Roberto. Sacrifício, mesa, festa e transe na religião afro-brasileira. Horizontes Antropológicos, Porto Alegre, v. 2, n. 3, p. 31-38. 1995. 
. Comida, família, dança e transe: sugestões para o estudo do xangô. In: Revista de Antropologia, São Paulo, v. 25. p. 147-158. 1982.

MOREIRA, Antonio Flavio Barbosa; CANDAU, Vera Maria. Educação escolar e cultura(s): construindo caminhos. Revista Brasileira de Educação, Rio de Janeiro, n. 23. p. 156-168, 2003.

OLIVEIRA, Amurabi. Etnografia e Pesquisa Educacional: por uma descrição densa da educação. Educacao Unisinos, São Leopoldo, v. 17, n. 3, p. 271-280, 2013a.

. O Aluno e seu Corpo. Revista Ibero-Americana de Estudos em Educação, Araraquara, v. 8, n. 1, p. 145-160, 2013 b.

. Por que Etnografia no sentido Estrito e não Estudos do Tipo Etnográfico em Educação? Revista FAEEBA, Salvador, v. 22, n. 40, p. 69$82,2013 c$.

OLIVEIRA, Kiusam Regina de. Candomblé de Ketu e educação: estratégias para o empoderamento da mulher negra. Tese (Doutorado em Educação) - Faculdade de Educação. Universidade de São Paulo. São Paulo: 2008.

ORTIZ, Renato. A morte branca do feiticeiro negro. São Paulo: Brasiliense, 1999.

PIRES, Flávia F. O que as crianças podem fazer pela antropologia? Horizontes Antropológicos, Porto Alegre, v 16, n 34, p. 137-157. 2010.

. Pesquisando crianças e infância: abordagens teóricas para o estudo das (e com as) crianças. Cadernos de Campo, São Paulo, n 17. p. 133151, 2009.

. Ser adulta e pesquisar crianças: explorando possibilidades metodológicas na pesquisa antropológica. Revista de Antropologia, São Paulo, v. 50, n 1. p. 225-270, 2007.

PRANDI, Reginaldo. O Brasil com axé: candomblé e umbanda no mercado religioso. Estudos Avançados, São Paulo, v. 18, n. 52. p. 223-238, 2004.

. O candomblé e o tempo: concepções de tempo, saber e autoridade da África para as religiões afro-brasileiras. Revista Brasileira de Ciências Sociais, São Paulo, v. 16, n. 47. p. 43-58, 2001. 129, 1995.

. Raça e religião. Novos Estudos Cebrap, São Paulo, n. 42, p. 113-

RABELO, Miriam Cristina. Entre a casa e a roça: trajetórias de socialização no candomblé de habitantes de bairros populares de Salvador. Religião \& Sociedade, Rio de Janeiro, v. 28, n. 1. p. 176-205, 2008. 
RABELO, Miriam Cristina.; SANTOS, Rita Maria Brito. Notas sobre o aprendizado no Candomblé. Revista FAEEBA, Salvador, v. 20, n. 35, p. 187-200, 2011.

SACRISTÁN, José Gimeno. O aluno como invenção. Porto Alegre: Artmed, 2005.

SARMENTO, Manuel J. As culturas da infância nas encruzilhadas da $2^{\text {a }}$ modernidade. In: SARMENTO, Manuel J.; CERISARA, A. B. (Org.). Crianças e miúdos: perspectivas sócio-pedagógicas da infância e educação. Porto: Asa, p. 9-34, 2004.

SARMENTO, Manuel J. A reinvenção do ofício de criança e de aluno. Atos de Pesquisa em Educação, Blumenau, v. 6, n. 3. p. 581-602, 2011.

SOUSA, Kássia Mota. Entre a escola e a religião: desafios para crianças de candomblé em Juazeiro do Norte. Dissertação (Mestrado em Educação) - Faculdade de Educação. Universidade Federal do Ceará. Fortaleza: 2010.

TASSINARI, Antonella M. I. O que as crianças têm a ensinar a seus professores? Contribuições a partir da Antropologia. Antropologia em Primeira Mão, Florianópolis, v. 5, n. 130, p. 1-20, Florianópolis, 2011, . VERGER, Pierre. Orixás: deuses iorubás na África e no novo mundo. Salvador: Corrupio, 2002.

Recebido em 1\%/08/2013

Aceito em 05/09/2014 